\title{
Analysis on Recluse Culture and Expansion of Aesthetic Vision on Ancient Literature
}

\author{
Liyu Chen \\ Sichuan Huaxin Modern Vocational College, Chengdu Sichuan, 610000, China
}

Keywords: Recluse culture, Ancient literature, Aesthetics.

\begin{abstract}
Dating back to the development process of Chinese historic culture and literature, recluse culture has played an important role in the overall development process. In the recluse culture, scholars regard the natural views as the intuitional objects and extol greatly. Independent aesthetic angel and appreciation conception has formed with literature works output are more fitting with natural views. This article makes a brief analysis on the natural background of recluse culture, specifically explains the integration of recluse culture and individualized literature aesthetics, and forms a scenario analysis within the entire aesthetic scope.
\end{abstract}

\section{Introduction}

In the developing history of Chinese culture, recluse culture has distinct era characteristics and inheritance spirit. Scholars and poets in ancient time used recluse culture as a special culture construction model. It is not difficult for us to find by analyzing basic historical materials, the applicable people of recluse cultures are divided into three types: first, due to inconformity of political views, some politicians dropped out from state affairs, or friends did not join in basic political discussion. These people have formed the recluse political existence. Second, some scholars were rational when pursuing material desires and eliminated the components of fame and wealth in the life. The basic living model is elegant. Thirdly, people were close to nature in their life and had inherent love for nature. They showed unintentionally their feelings for nature and formed basic living attitude of expressing emotions through sceneries.

\section{Recluse culture's influence on scholars' feelings.}

After the research on Chinese traditional culture, the article will summarize the social background of recluse culture prevailing in Chinese scholars from the change of time. Due to the traditional feudal social essence, the political environment at that time was not clear and bright. So some feudal scholar-officials cannot express their feelings fully. Under the influence of the whole feudal ethics and rites and political atmosphere, scholar-officials felt deeply disabled to make life and literature creation and started realizing that it was a time when scholars cannot build independent consciousness. For scholars at that time, it would get impacted from the society if they used real emotion to comfort the common people, and only being worldly wise could they make themselves safe in that era. Due to this social background and literature development direction, many scholars started diversified developing structure and produced the rudiment of basic recluse culture. In feudal society Chinese economic structure was supported by agriculture so many unsuccessful scholars who had a lot of emotions started throwing themselves into the pastoral living a recluse life and started creating a large amount of relevant literature works. In the recluse culture, corresponding recluse can not only dig out scholars' perception and emotion toward the whole society, but can also effectively relieve the upset and anxious mood due to frustration. The basis to build relevant recluse culture is the 
voluntary action of scholar self. The construction of whole culture was finished by the promotion from relevant humanity idea. Perhaps the practitioners of recluse culture have different recluse mentality at the beginning but their basic pursuits are extremely same. That is to fulfill the basic feeling-scenery combination with the support of emotional sustenance on natural basis, and to fulfill the wholehearted devotion. They have shown the fear of nature and established a harmonious model together with nature. This emotion has fully influenced scholars' basic literature works ${ }^{[1]}$.

During the development of recluse culture, the description of nature has gradually changed. At first the natural description in "The Book of Songs" was the spreading and metaphor of virtue through the scene. The objective description of natural views were for better presenting the metaphor of virtues and behaviors and the basic images of mountains and rivers have been personalized upgraded. With the time changing, relevant scholars started the emotional and scenery delineative recovery. Their moral aesthetic on nature changed to rendering description on natural views. The most famous was Tao Yuanming who was the representative of the Georgian school. Although he worked as government officials at his early years, due to political factors, he resigned for seclusion and started the creation by using pastoral poems to express emotions. In the several years when his works were extensive with well-known reputation, the best one was "Returning to My Farm" representing the recluse culture and pastoral views. The relevant representatives of recluse culture have deeply combined the overall recluse culture with nature, but also have optimized their pursuit for aesthetics. In recluse culture, relevant scholars and poets tag the warm feelings into some natural views which can touch people' s heart so as to achieve the integration of human being and nature. Therefore, recluse culture has impacted on the whole emotion of scholars' creation ${ }^{[2]}$.

\section{Intuitional expression of recluse culture under literature aesthetic vision}

In Chinese literature works, the concentrated explanations of recluse culture in the literature context are in three aspects including the real reflection of the scene, the rich emotional expression of the scene and the innovative angle for scene description.

First is the real reflection of the scene. In the establishing and developing period of real recluse culture, most literature creators thought the reality was the essential description of nature and the essential natural way. Human beings must make sure the real look of human mind is the real moral refection. And relevant real records and literature works were the falling of the way of life and the description of aesthetic objects were with basic interests. Relevant literature creators have endowed the conception of literature work with real investment of emotions so as to combine natural view and emotions into literal creative life forming an integral part. In addition, in Tao Yuanming' s work, the real description of sceneries have been depicted with relevant emotions. For literature creators, they will arrange and output words according to personal emotions and intentions during the literature creation process. The combination with natural feelings is to make literature creators express their life thoughts into the landscape and idyll so as to reach a natural and pure state. Tao Yuanming has described directly the country yard and peaches and plum trees, and recorded his true feelings into the relevant views so as to form a special meaningful and real scene. In addition, in the development of recluse development, the real scene reflection is to ensure the basic feelings of natural ways. The integration of nature and life into the whole spiritual world through words can fully get people out of the time dilemma of slavery spirit. Thus, recluse culture is the concentrated expression of author' $s$ real creation scene and mental state. The basic support of this expression way lies in the basic perception of natural objects. Nature can improve the scenery connotation of overall recluse culture, but also can provide basic topic and creation moments for literature creators ${ }^{[3]}$.

Second is the rich expression of the scene. The expression technique can be bright and wired and harmonious. But the most recommended in recluse culture is to make real emotional expression on words. The whole literature style has no congenial wording or threadbare expression. The most famous is Tao Yuanming, in his works the description and expression of natural sceneries are most real sentences fully showing his personal expression feelings and state of mind. Not like the worldly 
vision and comments, he combined the nature with his works, and made a direct complaint on feudal rites. Only by keeping this emotions can he really get far wary from the flashy and blatant world, truly understand the substantial condition of natural views and even-tempered humanity atmosphere. In relevant works produced in recluse culture time, people' $s$ freedom and simplicity in natural world were recorded and expressed in most real words to describe the most actual natural views and humanity sceneries for readers. The descendants think only ensuring the basic simplicity and plain of ancient poems when they comment the recluse poems can they feel the most waving inward world of poets. Inspecting from the most rich point view can really help literature go forward to more natural creation domain ${ }^{[4]}$.

At last the innovative angle for scene description cannot be changeless in the process of any art. Only corresponding innovation and development can produce more stimulating motivation so as to promote the progress of relevant literature form. In the literature creation of recluse culture, new structure has been introduced and replaced. There are some modifications of traditional cultural pattern to form innovative creation thinking and explore basic pathway of expressions in special and different ways. For the basic development of recluse culture, this new angle is based on the basic aesthetic idea not only to construct new model on literature creation contents but also to make breakthrough from the overall creation angle. It requires relevant literature creator to update topics and ideas in practical creation process, to ensure their positive perception on nature at any time and to feel deeper emotional experiences in the landscape scenes. For literature creators of recluse culture, innovative creation thinking is extracted and dig out from the most ordinary natural views, or is refined deeply from some views with special perceptivity ${ }^{[5]}$. Only to make sure the expansion of the basic perceptive scope of nature can they understand deeply the essence of nature and form richer literature creation materials. Innovative angle on scene description can make sure recluse culture can be developed innovatively. Only in this developing mode and state can recluse culture form natural complex.

\section{Individualized color expression of recluse culture under literature aesthetic vision}

Analyzing from psychological aspect, recluse life mode is the respect to life and liberation of the past. It is the further exploration for life meanings in the scene which can not only improve the subject' $\mathrm{s}$ independent consciousness but also can help the subject establish free and positive life mindset. Zhuangzi thinks that, people who lives recluse life do not go out usually or hibernate in the world but they never completely refuse the communication and exchange with the outside, or intentionally hide for others' seeking. The real reclusion is the mind to view world and the promotion of thinking in another life mode and concept. In the time when recluse culture prevailed, people' s behaviors were influenced and limited to a large degree. Their social responsibilities and official career were hindered by the intangible social power so that the corresponding social environment produced the pulling force. In the social situation range of recluse culture, the social spirit of natural detachment influenced the scholars' unappreciated mind so as to produce specialized literature works. They connected their feelings with daily life in their works and this promoted the production and development of basic works. In addition, in the development process of real recluse culture, the production and development made scholar-officials desire to get rid while abiding with the feudal rites under the time background. Recluse culture has made deep analysis on the mutualism connotation of nature and human beings, essentially making relevant literature creators feel and realize relevant mood in life and the whole life awareness. In recluse culture, the respect for individual life is more focused which means the individual refection of creation connotation and practice. Therefore, in recluse culture, the idea of literature aesthetics has gradually intensified and deepened driven by humanism.

Moreover, in the development process of recluse culture, what reclusion people focus is the organic integration of daily life and time background. Placing individual characters and emotions into 
relevant works has formed the reappearance and upgrade of life scenes. Multi-component humanity and emotion factors have been combined in this kind of articles including the author' $s$ feeling and admiration of natural scenes, author' $s$ feelings and love for basic human-ethics culture, and author' s devotion to friends and hometown. Relevant works are not only the presentation of basic characters and life, but also are penetrated with rich emotions. These works have described basic personality ideal and social requirement from the other side so as to produce a romantic literature artistic atmosphere. In the work expression process, the interweaving of humanity feelings and the awareness of social responsibility make relevant works endowed with bright epochal colors and personalized features. So literature works produced under the recluse cultural background have achieved essential recovery.

\section{Conclusion}

To sum up, researches on recluse culture can not only help literature workers to conduct basic background analysis on relevant literature works, but can also help traditional culture historian construct the structure of overall social culture. In the process of establishment and perfection of Chinese ancient literature domain, recluse culture takes an important position and essentially expands the whole vision of literature aesthetics. It has not only satisfied the social research on feeling-situation combination, but also has achieved necessary artistic reference. It has produced powerful promotion on the real refection of scene, rich emotional expression and the angle selection of scene description. Recluse culture has provided the most optimized literature reference for the development of Chinese literature and has promoted the integration of culture and literature to a degree.

\section{References}

[1] Song Zhanjiang. Evolution of Jiangzhou recluse culture and the writing style in Jin Song dynasty. Journal of South-Central University for Nationalities (Natural Science Edition), 2014,39(05):132-136.

[2] Lin Xiaona. Discussion on characteristics of recluse culture in North Song Dynasty . Journal of Southwest University for Nationalities (Natural Science Edition) 2014,10(06):184-190.

[3] Li Changshu. Buddhism foundation of Chinese ancient recluse culture. Journal of Nanjing University (philosophy, humane studies, social sciences),2014,51(06):131-137.

[4] Han Liu, Zhao Shuying. Poetic Dwelling: Mysterious farming life of Tao Yuanming. Journal of Xi'an Jiaotong University (Natural Science Edition),2014,34(01):102-106.

[5] Huo Jianbo, Xu Hao. Discussion on Tao Yuanming under the vision of recluse culture. Journal of Yanan University(Natural Science Edition),2015,26(02):91-93. 